\title{
Tracking the history of the North American Ice Sheet during the Last Glacial Cycle
}

\author{
R.L PARKER ${ }^{1 *}$ G.L FOSTER $^{2}$, M. GUTJAHR ${ }^{3}$, P.A. \\ WILSON $^{2}$, K. LITTLER ${ }^{1}$, M.J. COOPER ${ }^{2}$, A.MICHALIK ${ }^{2}$, \\ J.A. MILTON ${ }^{2}$, I. BAILEY ${ }^{1}$ \\ ${ }^{1}$ Camborne School of Mines, University of Exeter, Penryn \\ Campus, Cornwall, TR10 9FE, UK (*Correspondence: \\ rp501@exeter.ac.uk \\ ${ }^{2}$ School of Ocean and Earth Science, University of \\ Southampton, National Oceanography Centre \\ Southampton, Southampton, SO14 3ZH, UK \\ ${ }^{3}$ GEOMAR Helmholtz Centre for Ocean Research Kiel, \\ Wischhofstr. 1-3, 24148 Kiel, Germany
}

Continental ice-sheets play a major role in regional and global climate change. Knowledge of ice-sheeet extent is also important for glacial isostatic adjustment modelling of interglacial sea-level ${ }^{1}$. However, relatively little is known in detail about the history of continental ice sheets prior to the Last Glacial Maxiumum (LGM). Of key interest is the North American Ice Sheet complex, the volumetrically most important ice sheet in the high northern latitudes. The $\mathrm{Pb}$ iostope composition of the authigenic FeMn oxyhydroxide fraction in marine sediments deposited proximal to North America is a promising tool to track regional chemical weathering intensity and solute flux associated with glacial extent on North America beyond the $\mathrm{LGM}^{2,3,4}$. Yet existing records are currently temporally limited to the LGMHolocene.

We present the first authigenic Fe-Mn oxyhydroxide derived $\mathrm{Pb}$ isotope and Rare Earth Elements reconstructions from Orphan Knoll ( IODP Site U1302/03) in the NW North Atlantic spanning the Last Glacial Cycle (LGC) and both the last (TI) and penulimate deglaciation (TII). We examine the history of change in this $\mathrm{Pb}$ isotope record during TI and TII and discuss the significance of its variability and orbital pacing during the LGC in terms of Northern Hemisphere icesheet (NAIS) evolution. The $\mathrm{Pb}$ isotope record shows a dramatic change across MIS 5/4 towards unradiogenic values, highighting the likely expansion of NAIS to coastal margins at this time.

[1] Dendy, S. et al. 2017. Quat. Sci. Rev., 171, 234-244.

[2] Foster, G.L \& Vance, D. 2006. Nature, 444(7121), 918912.

[3] Kurzweil, F et al. 2010. Earth, Planet. Sci. Lett., 299 (34), 458-465.

[4] Crocket, K. C. et al. 2012. Quat. Sci, Rev., 38, 89-99. 